\title{
Employee Retention - Challenges and Realities Faced by Corporates for New Recruits as well as Existing Employees
}

\author{
K M Ravi Kumar*
}

\section{Abstract}

Identifying and nurturing employee's talents and providing them the right opportunity to grow in the organization according to their skills, competencies, and wants will not only reduce attrition of the existing employees but also provide a congenial atmosphere for the new recruits to adapt to the changed scenario and settle-down faster.It will helps them in understanding and addressing the organization's goal and linking the same to individual achievements. The study reveals how identifying employee needs and providing them the right place in the organization to grow reduces the existing employees' attrition and provide the new recruits a better acceptance and support in the organization.

Keywords:Retention, Attrition, Skills, Competencies, New recruits

\section{Introduction}

Employee retention was, is, and will be a challenge for corporate human resources. In the current challenging market scenario, leading the competition is the only way to survive. You need competent talents to lead the competition. These talents need to be updated and upgraded,depending on the market requirements and technology changes. However, if your developed talents are not

* Assistant Professor, MATS Institute of Management, Jain University, Bengaluru, India; oruman55@gmail.com 
retained organization loses the edge in thecompetition that is critical for survival.Generally, a minimum percentage of attrition is common and healthy in any organization. However, when it comes to losing critical talents, itbecomes a crisis or a challenge for human resources to find a replacement in the shortest possible time.

Retentionof the new recruits to adapt to the changed scenario and challenges, and retaining the existing employees are the two types of challenges that employers encounter, which impacts the manpower segment. Lateral recruitment itself can become a cause of if not done with precautions.On the other hand,providing the right opportunities depending on the employee's expectations and requirements helps in retaining the existing talents.

The study reveals that manpower planning, employee movement matrix, providing the right opportunity to the existing talent to excel depending on their skills and competencies will not only retain talents but also develop an atmosphere congenial to the new recruits to adapt and settle-down faster.

\section{Literature Review}

Discussions and debates surrounding employee retention go back almost more than three decades. Many studies and discussions were carried out to find ways and means of retaining talents. The majority of such discussions were focused on the retention of existing talents.

A Study by Anitha (2014) explores employee engagement as a motivating as well as dedicating feeling to accomplish a task efficiently. The authors examined Kahn's model, and the findings of the model supported that good working conditions, safety measures, working hours, and positivity in the organisation aredirectly linked with employee engagement. The study defined engagement as anextension of commitment. It also elaborated on employee engagement more extensively and divided engagement into two areas, one being engagement with the job, and the other was engagement with the organisation. The study describes employee engagement as a long-lasting, positive, and motivational approach for employees that results in a high level of work involvedwith passion and dedication. The study definedemployee 
engagement as an individual cognitive state and thepositive behavior and emotions that lead them to work in tandem with the organisation's goals.

An exploratory study by Moncarz, Zhao, \& Kay (2009), concluded that the retaining of a good talented workforce reveals that the organisation has to create a positive environment for a conducive working atmosphere. The study analyzed that good and successful organisations respect their employees and try to make policies more flexible for the betterment of employees so that the desired level of employee engagement can be achieved. The result of the study showed that retention is the process in which an employer takes steps to prevent their key employees from switching jobs. The study described that retention is an effort by which an employer makes some good policies to retain talented employees toachieve the organisation's goals and success. The study concluded that a talented workforce has high worth to the organisations due to their expertise, knowledge, skills, and experience. It was also stated that organisation treats such employees as assets. The study found that good retention strategies lead to a greater time span in the organisation and also motivates them to do their job dedicatedly.

Study conducted in UK (Clark, 2001) shows that employee attrition results from primarily three reasons - job satisfaction, job characteristics and job security. Other factors the study reveals as resulting in attrition are use of initiative, work itself, and hours of work. The conclusion of the study is that jod dissatisfcaion is a 'real' issue that increases the chances of employee attrition.

Study by Smart \& Chamberlain (2016), in a sample of 5000 found that predictions about employees' stay or exit can be predicted based on factors such as culture - company culture matters in employee retention or attrition. Employers who score higher on career opportunities, culture and value are less likely to see higher attrition rate and more likely to retain employees. Pay also has a significant impact on employee turnover. The study finds that a $10 \%$ increase in employee compensation increased the chances of employee staying in the job even when moved to another role. Job title stagnation has significant impact on employee retention. For every 10 months the employee staganates in the same designation, the chances of the employee leabving the company increases by $1 \%$. 
The study concludes that there are factors of attrition over which companies do not have controm, but they can control for factors such as improved workplace culture, competitive base pay and career advancement of employees - and these are more likely to reduce employee attrition.

Subramony \& Holtom (2012) studied employee attrition and its linkages to customer-perceived service outcomes and financial performance. The study found that employee attrition disrupts relationship with existing customers and has negative outcomes for finaicial performance of the business. Also, the study found that the relationship between employee turnover and customer percieved brand image is mediated by customer evaluation of service. The study recommends focusing on training employees for customer orientation and creating positive work environment.

Another research (Anis, Nasir, \& Safwan, 2011) stated that good training and development exercises couldhigh up the rate of retention because these training help the employeesachieve their as well the organisational goal in time and get rewarded for their efforts. The study concluded that good knowledge-based organisationsare now emphasizing training and development activities. The study showed that the high growth of an organisation depends on the ability of its employees. Comprehensive training \& development programmes must be applied to achieve a high level of competitive advantage. The research concluded that good training programmes lead to a high rate of employee retention.

Yet another research by Bhojak \& Shakdwipee (2014) stated that financial perks arethe major factor on which the relationship between the employee and the intention to stay in the organisation can be measured. The study concluded that a competitive pay structure is a vital aspect that easily affects the level of retention. The research concluded that a good administrated compensation structure plays a vital role in retaining the employees.

Another study (Khatun, 2010), observed that the retail industry is facing critical problems of acquiring and retaining workforce and is under severe shortage of talented professionals while it provides the largest number of employment opportunities to the Indian 
youth. Due to high levels of stress and lack of proper career plans, many young professionals are leaving the industry. As the retail industry continues to grow, employee retention is likely to remain a big challenge. However, her studies are confined to the retail industry's attrition levels.

A study in knowledge intensive industry (Yalabik, Swart, Kinnie \& Van Rossenberg, 2017) throws light that employee attrition has negative correaltion with organizational commitment and team commitment. Also, higher committment to profession is assoiciated with employees intention to quit.

A study (Lavanya, 2017) on employee attrition in the software industry examines employee, which is inevitable but manageable with software employees. A structured questionnaire was administered with a sample of 100 respondents. The findings demonstrated that there is no significant difference in the dimension of the factors as a predictor in explaining employees' attrition. The study revealed that there is a significant association in employee job seeking with that of the rate of attrition. This study attempts to provide a framework for employee attrition in software industries in South India.

This study has tried to address the attrition of both existing and new talents to get a holistic view of retaining talents, mainly in manufacturing industries, which is essential for business development and organisational growth.

\section{Objective of the Study}

The objectives of the study are mentioned below:

1. To reduce the attrition level of the entry-level employees by understanding and categorizing the new entrants as (a) emotional movements, (b) planned movements, and (c) multiple opportunity holders.

2. To reduce the attrition level of the existing employees due to lateral entry and overlapping responsibilities through job detailing. 


\section{Research Methodology}

The study employed a quantitative researchapproach. The quantitative approach was to capture concerns of employees, management, and recruiters in attracting and retaining talents in the changing scenarios and to get finer details of the participants' views and perceptions by asking respondents to elaborate and restate their views for better clarity. The population of the study comprised all organisations in Tamil Nadu industrial area and city, which is a hub ofmanufacturing industries. The researcher decided to study the manufacturing industries because these industries have faced serious growth challenges due to the lack of employee retention.

The researcher took samples from the ancillary companies operating in the Oragadam industrial area, Chennai. Five ancillary companies were selected for the purpose of this survey. Various categories of employees like staff, middle management, senior management were included in the survey. This survey was to find out the reasons for the attrition of existing employees. To find out the reasons for attrition of new entrants, the researcher took 130 samples from Koratti industrial belt, one of the prominent IT clusters in Kochi, Kerala

\section{Results and Discussions}

While discussing attrition, the first question that comes to anybody's mind is, 'Why do employees leave organizations?'. Many organizations and agencies had conducted various surveys to find out the exact reason for increased attrition. There is an old saying which that states, "Employees never leave an organization; they leave the boss," meaning if the boss is considerate, cooperative, and focuses on employee needs and wants, then attrition can be less. Some other survey revealed that if an organization provides adequate growth opportunities and encourages their employees to express their views, the attrition can be brought under control. The well-known employee satisfaction survey conducted by Gallup, known for their opinion polls, revealedthat when employees are provided with benefits according to the hierarchical needs, then their sense of belongings can be 
increased and which would reduce attrition. While another theory states that an employee leaves an organisation for monetary benefits, which has been totally opposedby many people. In short, many theories have been floating around,but there is no exact conclusion that points out the exact causes of the increase in attrition. The reasons vary from organisation to organisation and change according to situations.

One of the major contributors to high attrition is the failure of management to manage the expectations of the employees. Managing expectations varies according to the position and situation. Every organization has unique advantages and characteristics. The freedom enjoyed by the employees in a professionally managed company may be different from that of an owner-driven company. A start-up will have a lot more restrictions on facilities, investments, and ROI when compared to a wellestablished and cash-rich business firm. The candidates' mindset and expectations are very important to adapt to the circumstances, even if they have the requisite skills and competencies. Thus, along with skill and competencies, the attitude becomes equally important to retain talent in an organisation.

Yet another reason for high attrition among the employees is the artificial brand-boosting by the management to attract talents from the market. The management or HR tends to sketch a rosy picture of the position or business inorder to attract talents. Thus, the employee joins the organization with high expectations and, when faced with realities, tend to leave the organization in a short period. This not only creates an imbalance in the professional system but also negatively impacts affects the image of the brand.

\subsection{Attrition among New Recruits}

Generally, there are two major employee movements: (1) Emotional movement, (2) Planned movement while selecting talents from outside.

Emotional movement: Employees tend to leave an organization for various reasons, which include: (a) denialof a promotion or increment (b) an unexpected promotion or increment of a colleague (c) repeated discrimination by the boss or management. 
All these aspects may be a feeling, yet the employee is emotionally drained due to these aspects and decide to search for a change in employment. Such employees tend to accept the first offer they get just to move out of the uncomfortable situation or working environment. These types of employees generally tend to develop frustration once the initial un-comfortableness eases out due to change in the circumstances. They either look for another chance in the shortest possible time or go back to the parent organization if they are offered the denied promotion or increment by the company. Human resources, especially the recruitment team, should find out the reasons for employees leaving and ascertain the "want" of the employee on the employment change.

Planned movement: At the same time, if an employee is looking for a change in a planned manner, like enhancement of responsibilities, stagnated growth in an organization due to business reasons, opportunity to improve skills and competencies, application of acquired skills and competencies in case of a knowledge worker, such employees tend to stay for a longer tenure as long as the organisation satisfies their needs.

Multiple opportunity holders: Some employees tend to both emotional and planned job seekers; they hold multiple offers due to indecisive behaviour patterns. Such employees generally are skilled and experienced knowledge workers. These job seekers are clear about what they want when they decide to move out, but are not sure about an industry. They hide their expectations orare mentally not clear on "what they want" These employees tend to show a "trial and error" method. However, it is not difficult to identify such employees during the interview.

A survey conducted by NIPM, Ernakulam (Kochi) chapter, during 2015-16, in Koratti industrial belt, Trichur District, Kerala, and Angamali-Chalakkudi belt in Kerala, revealed interesting results.

There was a sudden surge of small and medium-size service-based IT companies in Koratti and Angamali. A good number of middle management staff moved to these areas from other parts of Kerala and other states. However, these industries witnessed a high level of attrition among the middle management that affected the productivity and profitability of these organizations. NIPM, with 
the help of management students, conducted a survey interviewing around 130 employees in various organizations;about 15 HR professionals were responsible for recruitment, and 30 technical professionals were the part of management responsible for organization delivery. While analysing the data, they found that new joiners tend to change their jobs within 3 to 6 months, and once they cross sixmonths, they tend to adjust more to the new culture and organizational demands and gets stabilized once they complete one year or more.

The survey revealed that new employees who look for a new job due to emotional decisions like denial of a promotion or increment tend to join back their parent company within one to three months. These employees get an offer from their parent company,which revokes their decision after they are offered the aspired promotion or increment. The majority of these employees tend to leave the organization without intimation or notice, and the parent company accepts them without a reliving letterand, in some cases, with continuity of service.

More than $80 \%$ of the sample selected revealed that the decision of moving out of an organization comes as emotional decisions due to an unexpected or unacceptable decision by the management. The majority of the employees take the decision of leaving the organization either because they were denied promotion/ increment or due to an unacceptable colleague beinggiven the promotion/increment. This unacceptable decision of the management causes a surge of emotion, which results in the employee moving out of the organisation. However,settlingin a new environment is a tough task for each employee.The employees face the following problems when they join a new organsation:

a) The employees have to prove themselves in the new organization with the changed policies, work environment, and new colleagues.

b) Their achievements in the previous organization havebecome history, and they will not get any benefits for them in the new organization.

c) There is no guarantee that the same success story can be repeated in the new organization. 
The majority of the employees who make changes on an emotional ground feel that if they put in the same effort that they putin the new organization, they can make a better impression in their parent organization.

Moving back to the parent organization by some of the employees when they were offered the promotion or increment denied by the management previously proved the above situation to be right. The majority of the employees expressed that they would like to go back to their parent organization if the management is willing to consider the denied promotion or increment for them. The employees'feeling of going back to their parent organization are obvious and more impactful during the first six months. Those employees who stay beyond six months started adjusting tothe new climate and remain in the position for better years.

Another group of employees opts for some offers from other employers almost for the same terms and conditions or with a minor increase in benefits, and these changes happen in the six months' time from their joining. The employees tend to leave without notice or intimation to the management. They either hide the six months of experience working in the new company or justify the decision pointing towards the delay in receiving the offer from the new company.

Under both the circumstances, the employees show disinterest or uncomfortableness in their present employment, and management can retain these employees by carefully addressing their needs.

The survey also revealed that those employees who make a planned movement to a better position or higher responsibility were happy and grew better in that organization. This shows that whenever an employee makes a planned movement for his professional growth and is mentally prepared to face the challenges in the new assignment, then that employee succeeds in the new job and grows further. 


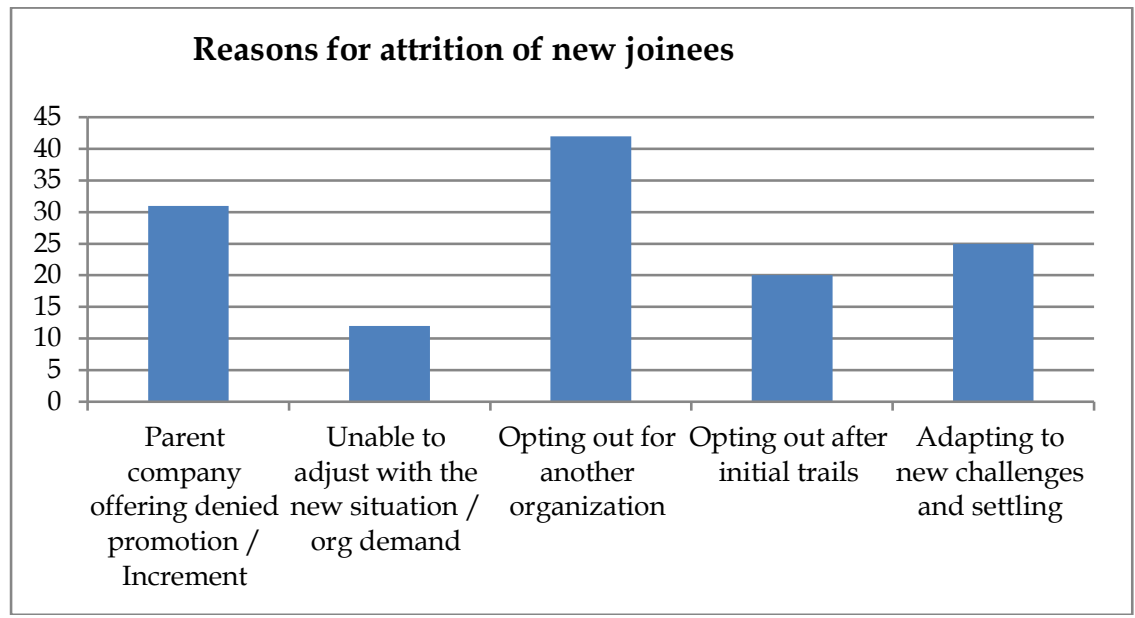

Out of the 130 samples selected, more than 32 new joiners went back to their parent organization when they were offered the denied promotion or increments within 1 to 3 months, and the majority of them left without notice or intimation.

About 12 new joiners went back to their parent organization because they felt that their parent organization had a better work atmosphere and easier tasks than the new one.These employees left within six months of joining

About 32 new joiners opted out to the new organization, and within ninemonths of joining, 25 new joiners continued their new jobs after accepting the challenges and adopting the new circumstances.

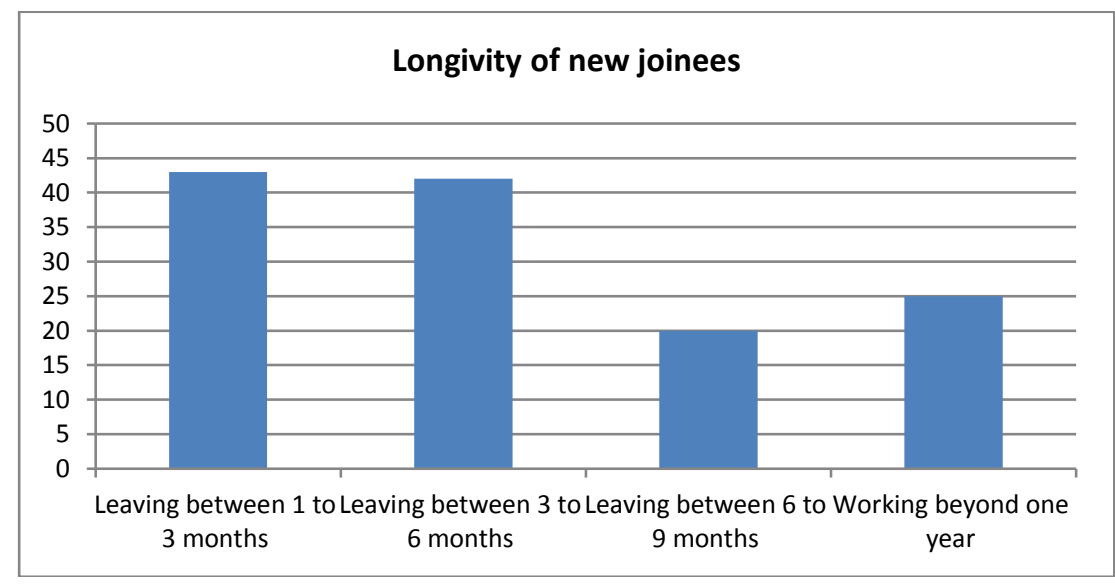


Out of the 130 samples selected, about 43 new joiners left the organization within threemonths, 41 left within sixmonths, 20 left between 6 to 9 months, and only 25 new joiners continued in the organization beyond one year.

The management was forced to offer additional salary and benefits to retain the employees, not only to the new joinee but also to the entire group to retain the talents and further arrest the talent erosion. However, this increased employee cost and drained the profitability of the organization.

Subsequent to the release of the survey data and discussions among the HR and functional heads, the recruitment team released "ONE PAGER" to ensure the interest and legitimacy of the candidature. Further, the recruitment team introduced initial screening by reference check and background screening. This improved the retention of talent by about $45 \%$ within a years' time. The maturing labor movement also was an accelerating cause for the improvement in retention.

Yet,other typical job seekers are those who keep changing their jobs. These types of employees lose their interest in an organization or employment, without any valid reason, in a couple of years. They tend to change their jobs for "small gains". Their main motive is a change of job. The new circumstance energizes these people. The profile of the job seeker itself will show the visible pattern of these job seekers.

Retention of these talents offers continuous professional challenges. In case they are in production or sales function, production of a new product or launch of a new product will energize them. If they are associated with the R\&D development of a new product or a variety will keep them engaged. At a higher level, these employees enjoy start-up or new projects. In short, they get energized with professional challenges and uncertainties.

Hence, to ensure retention of talents in an organization, management should ensure that the employee is looking for a change not because he is unhappy with the present management but he is looking for a growth opportunity that the current employer cannot offer due to business constraints. 


\subsection{Attrition among Existing Employees}

While attrition among the new recruits goes as stated above, the attrition of the existing employees assumes equal importance, if not more. In the changing circumstances and technologies, employees need to continuously improve their skills and competencies to stay where they are. Management keeps offering them a development program to ensure they are capable of delivering their assigned tasks.

While improving the talents- skills and competencies are essential for ensuring employee efficiency, which creates the threat of losing the talents if not taken precautionary measures.

On one side,certain organizations insist on "BOND" and employment agreements while offering training;these bonds and agreements have a fixed time limit and legal constraints. These steps were able to reduce attrition in some cases, but they were not able to improve efficiency and productivity to the desired level. Moreover, these bonds and agreements were limited to middle management. Senior-level employee attrition was more damaging and threatening to the management, especially when they were leading the competition.

Improving the compensation and benefits were one of the obvious ways of retaining talents; management had its own restrictions in implementing better benefits year on year. Moreover, management found that money loses its charm beyond a point. Especially in the Indian scenario, the more you earn,the more taxes you pay, employees turn back to management enquiring ways and means of legally avoiding taxes. Management too has found that the motivational factor in retaining an employee is not the monetary benefits, though monetary benefit plays a vital role in retaining employees

During 2017-18 couple of management associations conducted a survey to find out what causes high attrition among employees. They took 50 samples from eachcategory of employees, except worker level, as the attrition at that level was found to be low. They selected four categories: staff, middle management, senior management, and top management. 
Staff-employees at clerical and officer level. These employees were more of individual workers. Graduates or diploma holders, computer operators, etc.Their responsibility levels were limited to completing the assigned work and accuracy of data/result.

Middle management employees were more or less similar to staff level by way of qualifications, but holding a better responsibility, like sales officers on the field, employees grew to a manager level due to experience in the field, etc. Some of them had technical qualifications, like supervisors on the shop floor, quality assurance officers, etc. They were responsible for the assigned job/role responsibility.

Senior Management employees were at the level of department heads, like Regional Managers. They possessed management qualifications and considerable experience in their field of work. They were responsible for functional performance.

Top management employees were functional heads at the corporate level, with management qualifications from premier/ known institutions. They were decision-makers and responsible for the profitability of the business/organization.

They conducted the survey based on a structured questionnaire with18 questions, covering the aspects of basic facilities, job security, development and career progression, and freedom of work. All categories of employees were given the same questionnaire, and the data were collected by explaining the questions under supervision. The survey was conducted in Oragadam, an industrial belt in Chennai, Tamil Nadu. Survey results had the limitation of location, specific industry, and a onetime data collection. The survey revealed that reasons for attrition vary according to the position of responsibilities.

Some of the findings are reproduced in a chart form for the convenience of reference. 

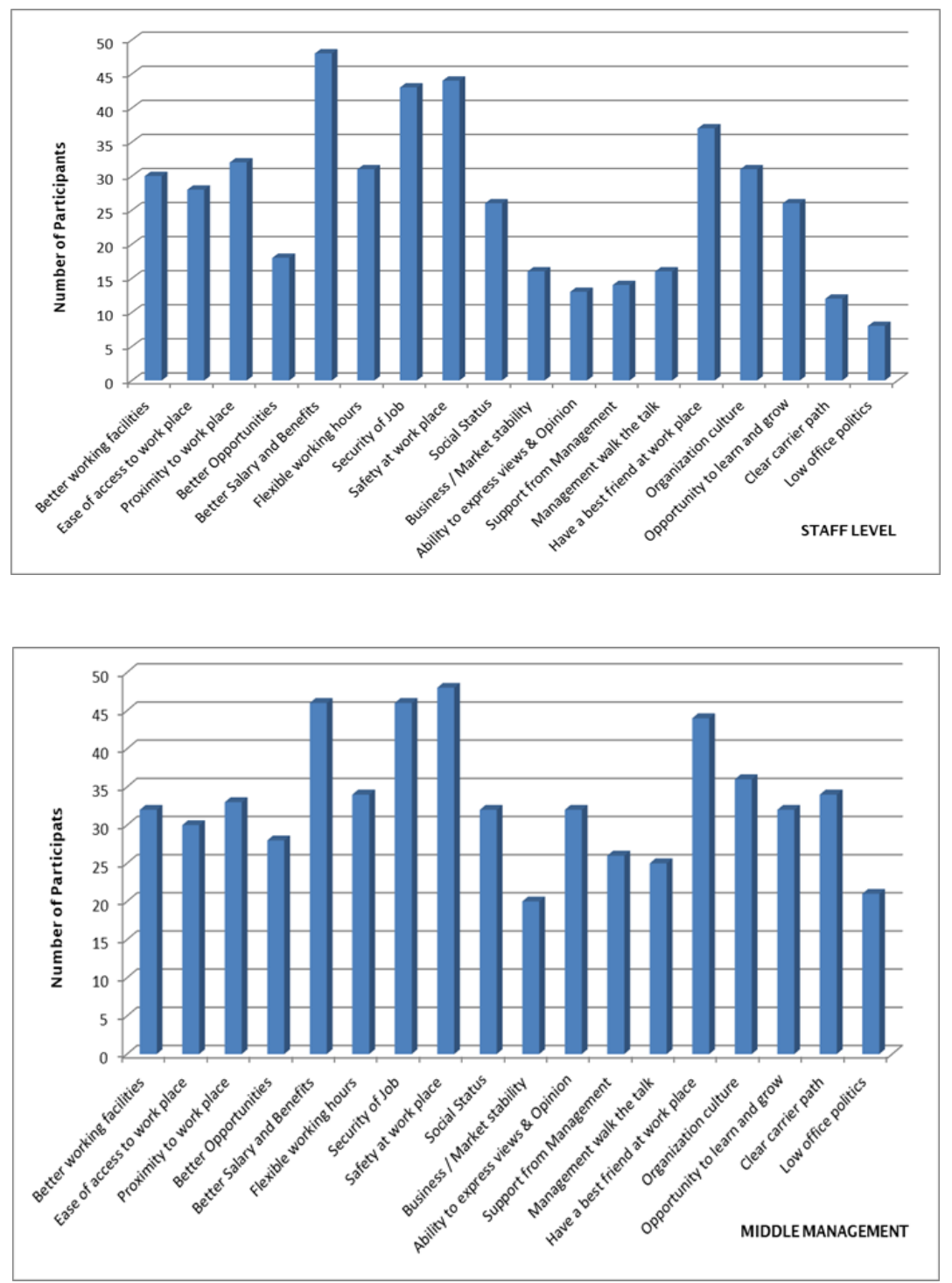

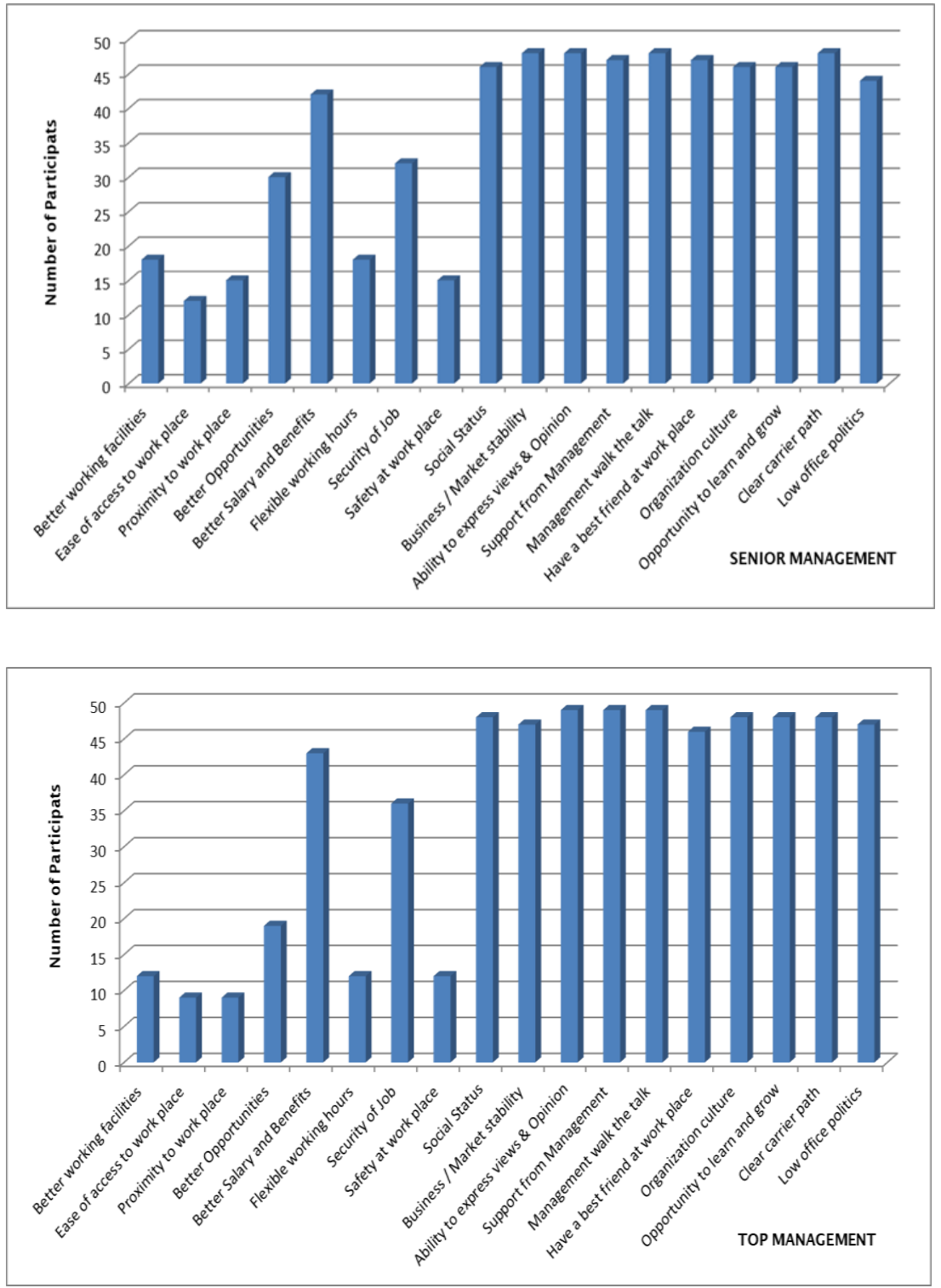

These findings are indicative and not conclusive, as these results are being debated. 


\subsection{Result of the data analysis revealed the following observations}

- Attrition among the new joiners is due to "emotional decisions" to join the new company and employees who are holding multiple opportunities.

- Employees who joined with a planned career growth plan tend to remain in the company for a longer period and thereby reducing the attrition level.

- Newly joined employees left when they realized the projected brand image and the actual working atmosphere were different. The artificial image bosting has resulted in high attrition among the new joiners at all levels.

- Middle management attrition was mainly due to internal competition resulting from overlapping responsibilities that created uncertainty and insecurity in the job.

- Lateral recruitment without offering these positions to internal talents created a demotivating effect among the employees that contributed to increased attrition level.

- Senior and top management category of employees were concentrating on their career growth, social status, business stability, self-development and freedom of expression, and decision making.

- The majority of attrition among experienced employees wereattributed to dissatisfaction in the appraisal process or evaluation method. These employees showed a low attrition level when transparent evaluation methods were adopted.

\section{Conclusions and Recommendations}

On analysis ofthe data collected as mentioned above, the following conclusions were made:

Attrition happens in all industries, and some percentage of attrition is unavoidable and healthy for an organisation. However, when the attrition impacts business uncertainties and acts as a threat to the organisation's development, it needs to be controlled. Attrition happens in the new entrants and existing employees. When 
management focuses on nurturing and developing talents, providing adequate opportunities for employees to experiment and exhibit their talents, generally attrition comes under control. Continuous communication, providing the big picture enablesthe employees to relate their targets with the organisation's goals, and employees develop loyalty and advocacy that reduces the attrition.

\section{Following recommendations are made:}

1. Manage expectations of employees. Understand their skills and competencies and provide opportunities that match their talents.

2. Ensure transparent and objective evaluation systems and counselling to educate employees and to manage their expectations in line with their skills and competencies.

3. Avoid artificial brand-boosting;it may give an initial boost to attract talents but will result in high attrition later.

4. While recruiting concentrate on job seekers having "planned movement" rather than "emotional movement" to reduce attrition among new recruits.

5. Avoid lateral recruitment unless the talent cannot be developed within.

6. Ensure clear "Job Design" and 'Responsibilities' to avoid overlapping of responsibilities and deliverables.

\section{Limitations and Further Scope of the Study}

The major limitation of this study is the locational constraint. This survey was conducted in the Tamil Nadu industrial belt and city. Limited participants were interviewed to collect the samples. The main concentration was made on manufacturing industries in Oragadam industrial belt in Chennai, Tamil Nadu.

The scope of improvement is to include various service industries and expand pan India, where locational preference, migration of talents, etc., can be included to come to a larger conclusion base. 


\section{References}

Anis, A., Nasir, A., \& Safwan, N. (2011). Employee retention relationship to training and development: A compensation perspective. African journal of business management, 5(7), 2679-2685.

Anitha, J. (2014). Determinants of employee engagement and their impact on employee performance. International journal of productivity and performance management.

Bhojak, Y., \& Shakdwipee, P. A Study on Employee Retention-Why Do Employees Stay with a Company with Special Reference to â Manufacturing Industry. International Journal of Modern Communication Technologies and Research, 2(8), 265769.

Clark, A. E. (2001). What really matters in a job? Hedonic measurement using quit data. Labour economics, 8(2), 223-242.

Khatun, R. (2010). Employee attrition-a challenge for the Indian retail industry. Journal of Business and Retail Management Research, 5(1).

Lavanya, D.B. (2017). A Study on Employee Attrition : Inevitable yet Manageable.

Moncarz, E., Zhao, J., \& Kay, C. (2009). An exploratory study of US lodging properties' organizational practices on employee turnover and retention. International Journal of Contemporary Hospitality Management.

Smart, M., \& Chamberlain, A. (2016). Why do workers quit? The factors that predict employee turnover. Glassdoor Research Report Whitepaper, 1-19.

Subramony, M., \& Holtom, B. C. (2012). The long-term influence of service employee attrition on customer outcomes and profits. Journal of Service Research, 15(4), 460-473.

Yalabik, Z. Y., Swart, J., Kinnie, N., \& Van Rossenberg, Y. (2017). Multiple foci of commitment and intention to quit in knowledge-intensive organizations (KIOs): what makes professionals leave? The International Journal of Human Resource Management, 28(2), 417-447. 